\title{
Do Horoscopes Influence the Process of Language Learning? A Model-Based Research Report Theme: Astronomy
}

\author{
Ch. Suvarna Ragini
}

\begin{abstract}
As teachers of language it is our common experience that we have to incorporate a plethora of teaching methodologies in our classroom situations. One specific way of teaching may not be suitable for the learners with different learning preferences and it may not always be receiving bouquets but brickbats too. Sometimes we even go to such a stage of contemplation that whether it is destiny which decides upon their learning potentiality.The main aim of the current study is to explore the relevance between the learners' horoscopes and learning abilities indicated in Reid's Perceptual Styles Questionnaire. And, in doing so it studied the variation in learners' preferences and their attitudes towards Language learning based upon the predictions made in their horoscopes.The parameters taken into consideration for testing their language abilities were Communication, Reading skills and Writing skills. Standardized Model Tests (GRE, TOEFL) were conducted to evaluate their performances andlater their performancescores were matched with the predictions made in their horoscopes. Interestingly $90 \%$ of the results indicated that the students' performances matched with the learning styles and preferences predicted in their horoscopes. Though the study needs further implications, it is believed that it providesthe teachers with the ability of classifying a mixed-ability classroom and designing relevant tasks to suit the learners' interests.
\end{abstract}

Keywords: Learning abilities, horoscopes, predictions, Perceptual Styles.

\section{INTRODUCTION}

Interpreting horoscopes to identify learning styles may be truly an unconventional area of research. Moreover, expressions like horoscopes and destiny regrettably sound antiquated and hackneyed without trying them in the Indian classrooms. Even though in the recent times astronomy has re-emerged as a science to be investigated in many curricula; there are many areas like teaching and learning difficulties which remain strange to astronomy education. At this point of time there is a need to establish theories which focus on teaching methodologies and hypothetical views which enable the teachers with the best practices in the educational institutions. Quite a few people think astrology is fun and completely of no use. Yet I strongly feel astrology is not going any place any time before long.

Apart from the fact that there is a desperate need to make sense of the mysterious chaos that is our universe, a question arises why does astrology still persist? Possibly there is some reality to the astrological scheme that our birth date has some relationship to certain aspects of our persona.

Revised Manuscript Received on December 16, 2019

Dr. Ch. SuvarnaRagini, Department of English, Chaitanya Bharth Institute of Technology, Hyderabad, India.

Email: suvarnaragini_english@cbit.ac.in
Moreover as an ELT practitioner I always contemplate about the possible interventions that could be incorporated into my instructional pedagogy. This thought prompted me to conduct a study to ascertain the relevance between the horoscopes and the language learning abilities of my students. Therefore the present study is a cross-sectional primary research based on empirical data to explore the relevance that exists between the learners' horoscopes and their learning preferences.

A model based upon the Reid's (1984)Perceptual Learning Style Preference Questionnaire (PLSPQ), a tool in the form of questionnaire and statements was used to correlate the data collected to explore the learning styles preferred by the learners. The corresponding dimensions were explored using exploratory factor analysis. Therefore the research questions for this study are:

i) What is a horoscope?

ii) What are the language learning abilities prescribed in Reid's Perceptual Questionnaire?

ii) What are the language learning abilities predicted in horoscopes?

iii) Can there be a relevance between the learning abilities predicted in horoscopes and the ones prescribed in the model used in the present study?

What does a horoscope mean?

According to Wikipedia it is the graphic representation or illustration indicative of the positions of the celestial objects like Sun, Moon and other planets at the time of a person's birth. Greek words hõra and scopos mean "time" and "observer". Astrologers design horoscopes based on constellation of stars and planets when a person is born which they believe will impact his or her behavioural traits, personality, mood and other factors.

In recent times, scientists have observed that astrologers can foretell one's fortune based on the time and place of one's birth. Occasionally a speck of specific forecasts may be erroneouseven though there is precision to the horoscopes.

\section{LITERATURE REVIEW}

On the occasion of the International Astrology Day, Gisele Terry told the Astrology Hub: "Astrology is in fact a global language. "We are all under the same sky sharing both our common and diverse perspectives on how we relate to the stars is the gift of International Astrology Day." March $20^{\text {th }}$ of every year is considered as the beginning of the astrological year.

The idea that the astrology can influence people's behaviour dates back to thousands of years. Though the thought has been largely dismissed by traditional scholars, new research suggests there may be some truth to these ancient theories. Gavrilov's (2009)

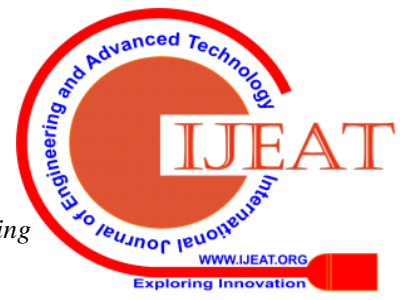


discoveries initially met with confrontation and misinterpretation [2]. He countered "People who are not familiar with the most recent scientific studies on this topic remain skeptical.Associating the work with astrology," he reiterates"but when we submit our findings to peer-reviewed professional journals, they are now very well received by experts."

SreeramRamagopalan, at the University of Oxford, accepts that the study of astrology is gaining impetus. He observed that the earlier studies had investigated an undersized sample of people -which indicated that it was difficult to ascertain that the outcomes weren't merely a matter of coincidence. He further adds, that in the last four or five years, there have been larger studies which have addressed those issues expansively. Ramagopalan's own studies looked at the health records of nearly 60,000 patients in England, viewing that children born in winter and spring are characteristically more at risk of schizophrenia, depression and bipolar disorders. Linda Geddes (2019) writes a complete story about how our association with light shapes our health, efficiency and mood [4]. She further strengthens the fact through her studies on influence of astrology on people's health.

However, very little research has been carried out in the field of educational implications regarding the relevance of the horoscopes and language learning abilities. Probably if I am not mistakenit could be the first of its kind of research.

\section{BACKGROUND TO THE STUDY}

Most of the Engineering students I teach come from rural background that belongs to different strata of the social structure where they lack enough exposure to English language learning. Therefore the teaching/learning of English in the classroom is greatly influenced by the various viewpoints and thinking styles of such students.

It was observed that their verbal and communication skills were limited in spite of brilliant aptitude and technical skills they possess. Jones (2007) comments that every class consists of a group of learners with different learning abilities [3]. Even students who have studied together continually will have divergent proficiency of the language. Some will be better at different language learning skills. They carry their own learning styles, personalities, strengths, and weaknesses to the class.

Only 25 percent of technical graduates are appropriate for employment in the outsourcing industry because of their inability to communicate well in English according to NASSCOM (National Association of Software and Services Company) President. The immense need for good communication skills in English has created a huge demand for English teaching around the world. Ragini (2019) notices that most of the learners lack good verbal and communication skills in spite of excellent aptitude and technical skills [7]. Millions of parents today wish their children improve their control over English language and make sure that they achieve a good mastery of the language. The worldwide demand for English has created an enormous demand for quality language teaching, language teaching materials and resources. Learners struggle to master English language to a higher level of accuracy and fluency by setting themselves challenging goals.At times, teachers experience frustration over their inability to help learners reach their goals.

Employers, too, insist that their employees have good language skills. It is surprising that despite the twelve years of prior exposure to language learning many of them lose the opportunities of lucrative job offers due to poor communicative skills. Hence apt communication becomes a precondition for professional achievement and progression in various areas of service in today's world. At the same time there are a few students for whom Communicative skills are a cake walk. Then there arose a need to search for an alternative intervention to identify and ascertain the reasons behind their shortcomings in mastering language skills.

\section{IV THE PRESENT STUDY}

The present study is based on 120 first year Engineering graduates (10 students belonging to each zodiac sign) was carried out for about 16 weeks (one semester) to explore the relevance between their horoscopes and learning abilities indicated in Reid's Perceptual Styles Questionnaire. And, in doing so it studied the disparity in learners' preferences and their attitudes based upon the predictions made in their horoscopes.

Initially a correlation between the learning abilities indicated in Reid's Perceptual questionnaire and horoscopes was identified. The study sample consisted of 120 students who were divided into twelve groups consisting of ten students in each group. The groups were categorized according to their zodiac signs. During the first semester the number of students belonging to respective zodiac signs was not sufficient. Moreover, there was a slight protest exhibited by a group of students belonging to a particular community who showed reluctance to take part in the study. Hence the study had to extend into second semester. Interestingly there were a few students belonging to the same community who were willing to participate in the study out of their curiosity.

The information about astronomy and horoscopes was collected from the following Google links on 3rd August, 2019.

1https://www.narcity.com/ca/on/ottawa/lifestyle/typestudent-based-zodiac-sign

2https://www.google.com/search?q=ramgopalans+study+on + astrology\&rlz=1C1CHBD enIN844IN844\&tbm=isch\&sou rce=iu\&ictx=1\&fir=MpKjWDgICm2irM\%253A\%252CQiT -fJjaC1gu2M\%252C_\&vet=1\&usg=AI4_-

kQdIxUUp31rtPUcroTjE8M14-R-

QA\&sa=X\&ved=2ahUKEwjY2ZTpqebjAhWJXSsKHRIfC TMQ9QEwAHoECAUQBg\#imgrc $=M p K j W D g I C m 2$ irM:

We further consulted astrology experts to gain knowledge about the features of astrology and its implications on human lives and their learning capabilities.

Learning styles indicated in Reids' perceptual styles questionnaire

\section{A. Visual Major Learning Style Preference}

The learners prefer looking at the text in the form of visual representation of information in texts, on the blackboards, and in workbooks to learn well. They memorize and comprehend information and instructions better if they read them. Oral explanation is not necessary for them as an auditory learner, however, they can often learn alone, by looking at the text and forming their own mind maps. They wish to write down the points of lectures and oral instructions if they want to remember the information.

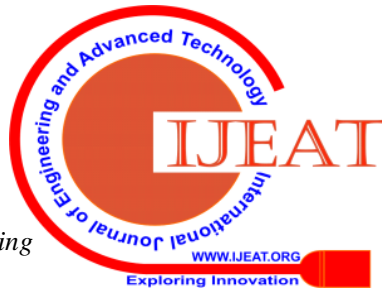




\section{B. Auditory Major Learning Style Preference}

The learnersprefer listening to spoken words and from verbal explanations. They may memorize information by reading aloud or uttering the words as they read, especially when they are learning unfamiliar material. Theyget benefitted fromlistening to audio tapes, lectures, and participating in class discussion. They also draw profits from making audio tapes to listen to, by teaching other students, and by conversing with their teacher.

\section{Kinesthetic Major Learning Style Preference}

They learn the best by doing the activity or by being involved actually in classroom learning activities. They remember information well when they actively take part in classroom activities. In other words they enjoy participatory kind of learning by actively involving themselves in activities like taking part in tours, enacting skits, and dramatics.

\section{TactileMajor Learning Style Preference}

Using materials in the process of learning is the most suitable method of learning for these learners. That is their learning process is guided by hands-on experiences. That is, carrying out experiments in a laboratory, handling and building models, and touching the things and working with materials. This kind of learning providesthem with the most rewarding learning situation. Instead of listening they prefer writing down the points or taking notes. Their memory will be enhanced when they move around and get involved in the classroom activities. It further helps them in the assimilation of new information.

\section{E. Group Major Learning Style Preference}

These learners cannot study in isolation. They always like to join with other students and prefer to work in collaboration. They give importance to group interaction and class work with other students, and they prefer to work with a group of learners to memorize information better. The inspiration they receive from collaboration helps them discover and appreciate information.

\section{F. Individual Major Learning Style Preference}

These learners learn best when they are alone. They imagine better when they study alone, and remember information when they are trained by themselves. They understand new material best when they study the material along with others. They make better advancement in learning when they work by themselves.

\section{G. Minor Learning Styles}

A majorityof learners learn in multiple ways that is their learning styles include a combination of methods. These can be described as versatile learners. They can adapt to any kind of teaching methodology. They can emerge as successful learners due to their multitalented and sophisticated learning styles. Their hidden talents can be manifested when they fall into the hands of skillful teachers.

\section{H. Negligible Learning Styles}

These learners generallytry to work on a few selective skills to fortifytheir learning styles in the minutest areas. signs.

Zodiac is the expression used to depict the circle of 12 sectors of celestial longitude that are centered upon the pathway of the sun. These 12 divisions are depicted as 12 different star signs whose constellations resemble different shapes of various forms. The astrologers believe that these 12 different star signs of the zodiac represent different traits, characteristic features and talents of individuals. These zodiac signs pertain to the individuals born between the dates given below:

\section{Leo (July 23 - August 22)}

They are the quick learners and take the lead role in guiding others. Their guidance is very helpful and since they soak up information very fast, they know exactly what they're talking about. They take learning very seriously, which is why becoming a teacher would be the best fit for Leos.

\section{A. Virgo (August 23 - September 22)}

Virgos are exceptionallypainstaking and they want everyone to know it. They always put their work first and are focused solely on their future. They don't brag about their grades, but they're very proud of their hard work and the time they put into it. They're natural learners, so they love learning about new things and it encourages them to be a better student. They don't strive for anything but the best.

\section{B. Libra(September 23 - October 22)}

Librans are typically at school to socialize and be around others. They love to 'study' in groups, and hate doing schoolwork alone. Leo's and Libra's would be great friends at school because of this. Libra's like to bounce ideas off of other people and always need others opinions to feel good about their work. They like the social aspect of school way more than the actual work.

\section{Scorpio(October 23 - November 21)}

Scorpios will go to the ends of the earth to find out information. They being fervent learners look at homework and projects as prerequisites and not asalternatives. School is the first preference to Scorpios.

\section{Sagittarius: (November 22 - December 21)}

This sign loves to explore what they're learning. Whether that's watching documentaries or going to the place they're learning about, it helps them connect with the subject. Sagittarius' are naturally spontaneous, so they would love to study history and take trips to ancient artifacts and monuments around the world. Like Tauruses, they are also hands-on learners and like to see what they are learning about to understand it.

\section{E. Capricorn: (December 22 - January 19)}

Capricorns just get the whole lot. And if they don't they're not afraid to sit through a lecture after raising their hand to ask a question. Their mind is always racing, and Capricorns also love helping people who don't understand. They are the leaders in every group project. 


\section{F. Aquarius: (January 20 - February 18)}

Being as creative as an Aquarius is bittersweet. They're very innovative, and think very carefully about how they will get things done to the best of their ability. However, they get frustrated when things donot go their exact way.

\section{G. Pisces: (February 19 - March 20)}

Pisces need everything to be perfect. They are very hard on themselves, and are very detail-oriented but can get stressed out over the littlest things. They over think everything in their life, but when it comes to school they need to prove something to themselves.

\section{H. Aries: (March 21 - April 19)}

They strive in group projects. They love to be noticed by their hard work and will never let anything get in the way.

I. Taurus: (April 20-May 20)

Tauruses learn better when what the learning is right in front of them, instead of written in a book. Tauruses make great chefs because they learn while working. They feel as though they remember things while actually doing them, which gives them the upper hand.

\section{J. Gemini: (May 21 - June 20)}

Gemini's learn things very quickly and will remember forever. It's rare for a Gemini to forget big details, and they also love helping people who don't understand. Gemini's can become obsessive when they find something they really love and will learn about it for hours on end. They're super picky learners and hate to learn about stuff they're not interested in.

\section{K. Cancer: (June 21 - July 22)}

Cancerians are always focused on their goals which makes them work super hard all the time. They value time and will always strive to get the best grade that they can. They are very persistent and never miss the deadlines.

The correlation between Reid's perceptual questionnaire and zodiac signs is shown in the following table.

Table-I: Correlation between Reid's perceptual questionnaire and zodiac signs

\begin{tabular}{|c|l|l|}
\hline S. No. & $\begin{array}{c}\text { Reid's Perceptual } \\
\text { Questionnaire (Preferences) }\end{array}$ & $\begin{array}{c}\text { Corresponding } \\
\text { zodiac signs }\end{array}$ \\
\hline 1. & Visual & Sagittarius, Scorpio \\
\hline 2. & Auditory & Capricorn \\
\hline 3. & Kinesthetic & Aquarius \\
\hline 4. & Tactile & Taurus \\
\hline 5. & Group major learners & Libra, Leo, Aries \\
\hline 6. & Individual major learners & Gemini \\
\hline 7. & Minor learning styles & Cancer, Virgo \\
\hline 8. & Negligible learning styles & Pisces \\
\hline
\end{tabular}

\section{METHODOLOGY}

Initially we gathered primary information from the sample students using Reid's questionnaire to collect information about their learning preferences. The questionnaire has been administered to help the learners to categorize the best ways suitable for the learners' preferences in the process of learning. There are thirty statements in the questionnaire and the learners have to respond to them by agreeing or disagreeing as they apply to their learning styles. This knowledge helped the researcher to ascertain the diversity in the learners' learning preferences.

Secondly ten students belonging to each zodiac sign took tests in three parameters namely; reading skills, Communication skills and Writing skills. The tasks were taken from the mock tests conducted for the standardized tests like GRE and TOEFL. Their performances were evaluated and their average mean scores were recorded for further analysis. The resultswere tabulated below:

Table- II: Mean scores of the students in 3 parameters
\begin{tabular}{|l|l|c|c|c|}
\hline S. No & $\begin{array}{c}\text { Students } \\
\text { according to } \\
\text { Zodiac signs }\end{array}$ & $\begin{array}{c}\text { Reading } \\
\text { Skill Test } \\
\text { Scores } \\
\mathbf{1 0} \text { M }\end{array}$ & $\begin{array}{c}\text { Communi } \\
\text { cation } \\
\text { Skills Test } \\
\text { Scores } \\
\mathbf{1 0 M}\end{array}$ & $\begin{array}{c}\text { Writing } \\
\text { Skills Test } \\
\text { Scores } \\
10 M\end{array}$ \\
\hline 1. & Leos & 9 & 9 & 8 \\
\hline 2. & Virgo & 6 & 7 & 6 \\
\hline 3. & Capricorn & 6 & 7 & 6 \\
\hline 4. & Aquarius & 8 & 8 & 9 \\
\hline 5. & Taurus & 6 & 8 & 9 \\
\hline 6. & Libra & 6 & 8 & 9 \\
\hline 7. & Gemini & 7 & 6 & 5 \\
\hline 8. & Cancer & 8 & 5 & 6 \\
\hline 9. & Pisces & 6 & 6 & 5 \\
\hline 10. & Sagittarius & 5 & 7 & 6 \\
\hline 11. & Scorpio & & 8 & 6 \\
\hline 12. & Aries & & & \\
\hline
\end{tabular}

\section{ANALYSIS}

The analysis of the present study shows that Leos, Aquarians and Librans could excel in Reading skills and Writing skills. When their answer scripts were evaluated it was evident that they could read with higher levels of comprehension. Similarly Taureans, Aquarians, Geminis and Aries could excel in Communication skills. Writing skills tests were enjoyed by the students belonging to Aquarius, Libra and Taurus. The remaining students could not perform well due to reasons unknown.

\section{IMPLICATIONS}

It is implied that the predictions made in the horoscopes regarding the students' language learning abilities were found to be true to a greater level. The study further implies that the characteristics mentioned in the questionnaire leading to the predictions made in horoscopes have significant impact on the

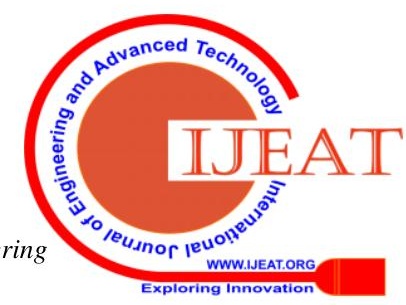


performance of the students. The study also suggests that it is necessary to follow different methods of teaching in a class with different learning preferences according to the preferences identified in their zodiac signs. There was a sarcastic remark made by a colleague in the staffroom when the study was discussed. The remark was that "Horoscopes make people feel good because of a psychological upshot known as the placebo effect. The placebo effect is when the conviction in a futile method essentially makes a person feel better. It is the belief itself, and not the method, that causes the improvement". However the students who have participated in the study hardly were aware of any predictions made in the horoscopes nor did they receive any formal training classes in the skills they were tested.

\section{CONCLUSION}

Though the study used Exploratory Factor Analysis, the researcher could notestablish the statistical power and significance level, in order to attain a factor loading of .55 with a power of .80.Though the sample of the study was 120 ,the number of participants was limited to 10 for each component. However, the results showed that specific items grouped into factors conceptually in the horoscope predictionswere compatible with Reid's learning style model.

The present study is not an approval of astrology but a shout out to science, which has turned up more than a few examples. It tries to ascertain the way our birthdates might influence our personalities especially in the way learners learn. There is still plenty of room for more research to firm up some of the findings on this list. The internentions which are carefully and systematically planned can be implemented to bring about the desired changes among the learners.

\section{FOLLOW UP ACTION}

The results from the current study suggested that further research can be conducted taking the limitations into consideration. The limitations of astronomical studies should be considered in relevance to learning preferences at educational institutions and teacher training institutions. It should further aim to publicize the outcomes more effectively within the learning systems.

Results also showed that there is a need to understand the reasons behind the diversification in the learning preferences among the students belonging to the same age group.

\section{REFERENCES}

1. C.I.T.E. Learning Styles Instrument, Murdoch Teacher Center, Wichita, Kansas 67208.)

2. [2] Gavrilov's (2009) https://projecteuclid.org/euclid.aoas/1239888367

3. Jones, Leo (2007). The student-centered classroom. New York, NY: Cambridge University Press.

4. Linda Geddes (2019) Chasing the Sunhttps://profilebooks.com/chasing-the-sun.html

5. https://www.narcity.com/ca/on/ottawa/lifestyle/type-student-basedzodiac-sign

6. Premji, Rishad, President- NASSCOM- The National association of Software and Services Companies

7. Ragini, Suvarna(2019) How to develop accuracy in speech and writing skills at tertiary level? A study report, International journal www.languageinindia.com Vol.19:2 February 2019.
8. Reid's Perceptual Learning Style Preference Questionnaire

9. (Copyright 1984, by Joy Reid.Explanation of learning styles was adapted from the C.I.T.E. Learning Styles Instrument, Murdoch Teacher Center, Wichita, Kansas 67208 )

10. Sheorey, Ravi (1991). An examination of language learning strategy use in the setting of an indigenized variety of English.System Vol 27.2 .

11. Shrivastava, Archana and J. Sundarsingh (2010). Coping with the Problems of Mixed Ability Students.Language in India Vol. 10.1.

\section{AUTHORS PROFILE}

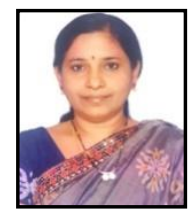

DrSuvarnaRagini, Ph D from EFLU, Hyderabad has 28 years of experience as English teacher. Currently she is teaching English language to $\mathrm{B}$ Tech students at Chaitanya Bharathi Institute of Technology at Hyderabad. She is also Academic Counsellor at EFLUHYDERABAD. Her areas of interest are reading and writing skills. She has published 25 Research papers in National andInternational Journals. She counsels Post graduate scholars as Academic Counsellor at EFLU-Hyderabad. She is a Review Committee Member for Palgo Research Journal Publishers and a Subject Expert in Interview Panel for ratification interviews. She has been awarded the best paper presenter at National Level Conference "On Literary Perspectives in the Arena of Modern Education"' (Nlclpame-2019) Hyderabad. 